\title{
COMmENT ON FLUOROSCOPIC INTERLAMINAR EPIDURAL StEROId INJECTIONS
}

\section{To the Editor:}

The article by Botwin et al (1) appears to strengthen conclusions from past studies that imply low efficacy of blind epidural injections $(2,3)$. Although the authors do not draw conclusions about efficacy, they cite the benefits of placing medication in the ventral space as was shown in other studies $(4,5)$. With the benefits of contrast enhanced image-guided fluoroscopic injections, we can assess our ability to precisely deliver medication to this space. In this new study the authors demonstrate that, in a fluoroscopically guided posterior, interlaminar epidural steroid injection, the medication injected will often (64 percent) fail to reach the ventral epidural space.

Previous studies without the use of fluoroscopy have demonstrated that only $70-87 \%$ of "blind" injections reach the epidural space at all $(2,3)$. The image-guided injections in Botwin's article were placed in the epidural space. Consequently, adding Botwin's data to the previous work we can say that, using blind epidural injection, the injectate will reach the ventral space only 25 to 31 percent of the time. Factors such as prior spinal surgery (increased epidural scarring), skill of the individual in location and placement of the needle and other variables can only reduce this level further. Spine surgeons who order these injections prior to considering surgery should be alert to the low likelihood of benefit of the blind epidural approach. This may spare the patient unnecessary surgery if a more effective treatment is offered, one that places maximum concentration/ controlled volume of corticosteroid most precisely at the inflamed lesion site.

In summary, we appreciate Dr. Botwin and his group for revealing important contrast study data that will ultimately lead us closer to the science (standardization) of where and why we perform our injections. An important conclusion can be drawn by combining data he presented in his article with that of other studies, which will hopefully help lead to the extinction of non-fluoroscopically guided spinal injections.

\section{REFERENCES}

1. Botwin KP, Natalicchio J, Hanna A. Fluoroscopic lumbar interlaminar epidural ste- roid injections: A prospective evaluation of epidurography contrast patterns and anatomical review of the epidural space. Pain Physician 2004; 7;77-80.

2. Mehta M. Extradural block. Confirmation of the injection site by $\mathrm{X}$-ray monitoring. Anesthesia 1985; 40: 1009-1012.

3. White AH. Injection techniques for the diagnosis and treatment of low back pain. Orthop Clin North Am 1983; 14: 553-557.

4. Lutz GE, Vad VB, Wisneski, RJ. Fluoroscopic transforaminal lumbar epidural steroids: An outcome study. Arch Phys Med Rehabil 1998; 79:1362-1366.

5. Andrade A, Eckman E. The Distribution of Radiologic Contrast Media by Lumbar Translaminar and Selective Neurals in Normal Human Volunteers. Proceedings of the International Spinal Injection Society Annual Meeting. Keystone (CO), 1992.

\section{Michael Hammer, MD}

Medical Director

Timothy Ramsey, Research Director The Hammer Center for Pain Management

2700 10th Ave. S. Suite. \#407

Birmingham, AL 35205

E-mail: hammermd54@aol.com

Pain Physician Vol. 7, No. 4, 2004 